\title{
Hubungan antara Pengetahuan dan Anemia Terhadap Kejadian Disminore Pada Mahasiswi Akademi Kebidanan Budi Mulia Palembang Tahun 2019
}

Leny

Akademi Kebidanan Budi Mulia Palembang

Informasi Artikel :

Diterima : 20 Mei 2020

Direvisi : 28 Mei 2020

Disetujui : 15 Mei 2020

"Korespondensi Penulis :

basorirayca@gmail.com

\begin{abstract}
A B S T R A K
Disminore adalah nyeri haid yang timbul menjelang atau selama haid. Angka kejadian disminore di dunia sangat besar, rata-rata lebih dari $50 \%$ perempuan di setiap negara mengalami disminore. Tujuan penelitian ini adalah untuk mengetahui hubungan antara pengetahuan dan anemia terhadap kejadian disminore pada mahasiswi Akademi Kebidanan Budi Mulia Palembang Tahun 2019. Penelitian ini menggunakan metode survei analitik dengan pendekatan Cross Sectional dengan menggunakan questioner. Populasi penelitian ini adalah seluruh mahasisiwi akademi kebidanan Budi Mulia palembang Tingkat 1 yang berjumlah 67 responden.sampel penelitian ini diambil secara non random sampling dengan sampel penelitian adalah total populasi yaitu seluruh mahasiswi akademi kebidanan Budi mulia Tingkat 1. Data yang diperoleh menggunakan analisis univariat dan analisis bivariat menggunakan uji statistik Chi-square. Hasil analisis univariat menunjukan bahwa mahasiswi dengan disminore $67,2 \%$ dan yang tidak disminore $32,8 \%$, didapatkan $60 \%$ responden mengalami disminore dengan pengetahuan baik dan $69,2 \%$ responden dengan pengetahuan kurang, $72 \%$ responden mengalami disminore dengan anemia dan 64,3\% responden tidak anemia mengalami disminore. Dari hasil uji Chi square menunjukkan tidak ada hubungan yang bermakna antara pengetahuan dengan kejadian disminore dengan p.value $=1,000$ dan tidak ada hubungan yang bermakna antara anemia dengan kejadian disminore dengan p.value $=0,236 \mathrm{di}$ Akademi Kebidanan Budi Mulia Palembang tahun 2019. Dari hasil penelitian ini, menyarankan agar peneliti yang akan datang dapat menambah variabel yang di teliti yang mempengaruhi kejadian disminore.
\end{abstract}

Kata Kunci : Kejadian Disminore, pengetahuan, anemia

\section{ABSTRACT}

Dysminorrhea is menstrual pain that occurs before or during menstruation. The incidence of disminore in the world is very large, on average more than 50\% of women in each country experience disminore. The purpose of this study was to determine the relationship between knowledge and anemia on the incidence of disminore in Budi Mulia Academy Midwifery Students in 2019. This study used an analytical survey method with a cross sectional approach using a questioner. The population of this study was all students of Budi Mulia midwifery academy palembang Level 1, amounting to 67 respondents. The sample of this study was taken by non-random sampling with the study sample was the total population ie all Budi Mulia midwifery academics Level 1. Data were obtained using univariate analysis and analysis bivariate using the Chi-square statistical test. Univariate analysis results showed that female students with disminore $67.2 \%$ and nondysminore $32.8 \%$, found $60 \%$ of respondents experienced disminore with good knowledge and $69.2 \%$ of respondents with less 
knowledge, $72 \%$ of respondents experienced disminore with anemia and 64, 3\% of respondents without anemia had dysminorrhea. Chi square test results showed no significant relationship between knowledge with the incidence of disminore with p.value $=1,000$ and there was no significant relationship between anemia with disminore with p.value $=0.236$ at the Budi Mulia Midwifery Academy in 2019. From the results this study, suggests that future researchers can add a study of variables that affect the incidence of disminore.

Keywords: Disminore events, knowledge, anemia

\section{PENDAHULUAN}

Kesehatan reproduksi adalah keadaan sejahtera baik fisik, mental, sosial, yang utuh dalam segala hal yang berkaitan dengan fungsi, peran dari sistem reproduksi wanita. Pengetahuan kesehatan reproduksi sebaiknya dilakukan sejak remaja, karena seseorang akan dapat mengenali kelainan pada kesehatan reproduksinya sendini mungkin, terutama tentang menstruasi. ${ }^{1}$

Disminore adalah nyeri haid yang timbul menjelang atau selama haid. Dikatakan nyeri haid (disminorea) bila nyeri yang ditimbulkan sampai membuat wanita tidak dapat bekerja dan harus tidur. Nyeri yang terjadi seringnya bersamaan dengan rasa mual, sakit kepala, perasaan mau pingsan dan mudah marah. Nyeri tersebut dirasakan oleh wanita pada bagian perut dan terasa sangat sakit. ${ }^{2}$

Disminore dibagi dalam dua macam, yaitu disminorea primer dan disminorea sekunder. Disminorea primer adalah nyeri yang muncul segera setelah menarke (sejak pertama mengalami haid), sedangkan disminore sekunder nyeri yag muncul setelah beberapa bulan mengalami masa haid. ${ }^{3}$

Disminore (nyeri menstruasi) dapat bersifat primer atau sekunder. Kelainan ini dikatakan terjadi pada $60-70 \%$ wanita dengan 15\%-nya mengeluh bahwa aktifitas mereka terbatas akibat disminore. Disminore primer timbul sejak menarche, dan mungkin di sebabkan oleh ketidak seimbangan prostaglandin. Disminore sekunder terjadi pada wanita yang sebelumnya tidak mengalami nyeri menstruasi dan mungkin berkaitan dengan endometriosis. ${ }^{4}$

Angka kejadian nyeri menstruasi (disminore) di dunia sangat besar, rata-rata lebih dari $50 \%$ perempuan di setiap negara mengalami dismenore. Di Amerika angka presentasenya sekitar 60\% dan di Swedia sekitar 72\%. Sementara di Indonesia angkanya diperkirakan 55\% perempuan produktif yang tersiksa oleh Dismenore. Angka kejadian (prevalensi) Dismenore berkisar $45-95 \%$ di kalangan wanita usia produktif. ${ }^{5}$

Haid yang tidak teratur disebabkan ada gangguan hormon/faktor psikis, yaitu stress dan depresi yang mempengaruhi kerja hormon. Banyak faktor-faktor yang mempengaruhi disminorea adalah faktor kejiwaan yang berkaitan dengan pengetahuan. Faktor konstitusi yang berkaitan dengan anemia dan penyakit menahun serta faktor endokrin yang berkaitan dengan endometrium dalam fase sekesi memproduksi prostaglandin F-alfa yang menyebabkan kontraksi otot-otot polos. ${ }^{6}$

Pengetahuan remaja tentang disminore amat sedikit sehingga mereka tidak tahu apa yang dilakukan jika nyeri datang, begitu juga sikap remaja mengenai disminore amatlah sedikit, kadang remaja berharap mereka tidak mendapatkam haid, mereka beranggapan haid merupakan hari yang amat menyiksa bagi mereka. $^{7}$

Pengetahuan kesehatan reproduksi yang kurang, terutama mengenai disminore pada saat menstruasi akan menimbulkan sikap kecemasan akan datangnya haid yang tidak menyenangkan dengan kata lain remaja mengembangkan sikap negatif tentang menstruasi. Diperkirakan 9,2\% penduduk remaja putri yang berusia 10-16 tahun sudah mengalami mentruasi . 7

Anemia adalah defisiensi eritrosit atau hemoglobin atau dapat keduanya hingga menyebabkan kemampuan mengangkut oksigen berkurang. Sebagian besar penyebab anemia adalah kekurangan zat besi yang diperlukan untuk pembentukan hemoglobin, sehingga disebut anemia kekurangan zat besi. Kekurangan zat besi ini dapat menimbulkan gangguan atau hambatan pada pertumbuhan baik sel tubuh maupun sel otak dan dapat menurunkan daya tahan tubuh seseorang, termasuk daya tahan tubuh terhadap rasa nyeri termasuk nyeri pada saat menstruasi. ${ }^{2}$

Dismenore dapat membuat seseorang menjadi lemah dan tidak bertenaga yang 
berdampak negatif pada kegiatannya sehari-hari dan secara psikologi akan sangat mengganggu, bahkan menjadi salah satu alasan tersering wanita tidak masuk kerja atau sekolah. Dismenorea cenderung terjadi lebih sering dan lebih hebat, pada gadis remaja yang mengalami kegelisahan, ketegangan dan kecemasan. Jika tidak diatasi, nyeri menstruasi ini sering kali akan mengganggu aktifitas dari remaja tersebut. ${ }^{7}$.

\section{METODE PENELITIAN}

Penelitian ini menggunakan metode survey analitik dengan pendekatan "cross sectional" dimana variabel independen (pengetahuan dan anemia) dan variabel dependen (kejadian disminore) dikumpulkan dalam waktu yang bersamaan. ${ }^{8}$

Populasi penelitian ini adalah seluruh objek penelitian atau yang teliti. ${ }^{9}$ Populasi dalam penelitian ini adalah semua Mahasiswi Akademi Kebidanan Budi Mulia Palembang Tingkat I. Sampel dalam penelitian ini diambil secara non random sampling dengan sampel penelitian adalah total populasi yaitu seluruh mahasiswi Akademi Kebidanan Budi Mulia Palembang Tingkat I.

Analisa univariat dilakukan untuk mengetahui distribusi frekuensi dari variabel dependen dan independen dari hasil penelitian, pada umumnya dalam analisa ini hanya menghasilkan distribusi dan persentase dari tiap variabel. ${ }^{3 \cdot}$ Analisa ini dilakukan untuk mengetahui distribusi frekuensi dari variabel dependen yaitu kejadian disminore dan variabel independen yaitu pengetahuan dan anemia.

Analisa ini dilakukan untuk melihat hubungan antara variabel dependen yaitu kejadian disminore dengan variabel independen yaitu pengetahuan dan anemia. Penelitian ini dilakukan untuk melihat hubungan antara variabel dependen dengan variabel independen menggunakan uji statistik Chi-square dengan tingkat kemaknaan $\alpha=0,05, \mathrm{CI}=95 \%$ bila $p$. value $\leq 0,05$ artinya ada hubungan bermakna antara variabel dependen dengan variabel independen, bila p.value $>0,05$ artinya tidak ada hubungan antara variabel dependen dengan variabel independen.

\section{HASIL PENELITIAN}

\section{a. Analisis Univariat}

\section{Kejadian Disminore}

Variabel kejadian disminore dibagi menjadi 2 kategori yaitu disminore (bila nyeri yang ditimbulkan sampai membuat wanita tidak dapat bekerja dan harus tidur ) tidak disminore (bila nyeri yang ditimbulkan tidak sampai membuat wanita tidak dapat bekerja dan harus tidur) untuk lebih jelasnya dapat dilihat pada tabel 1.

\section{Tabel.1.Distribusi Frekuensi Responden Berdasarkan Kejadian Disminore pada Mahasiswi Di Akademi Kebidanan Budi Mulia Palembang Tahun 2019}

\begin{tabular}{clll}
\hline $\begin{array}{l}\text { N } \\
\text { o }\end{array}$ & Kejadian Disminore & F & Persentase \\
\hline 1 & Disminore & 45 & 67,2 \\
\hline 2 & Tidak disminore & 22 & 32,8 \\
\hline & Jumlah & $\mathbf{6 7}$ & $\mathbf{1 0 0 , 0}$ \\
\hline
\end{tabular}

Berdasarkan tabel 1 di atas kejadian disminore sebanyak 45 responden $(67,2 \%)$ dan tidak disminore sebanyak 22 responden $(32,8 \%)$.

\section{Pengetahuan}

Pengetahuan dibagi menjadi 2 kategori yaitu baik (jika $\geq 75 \%$ pertanyaan dijawab benar), kurang ( jika $<75 \%$ pertanyaan dijawab benar) untuk lebih jelasnya dapat dilihat pada tabel 2.

Tabel 2 Distribusi Frekuensi Berdasarkan Pengetahuan Di Akademi Kebidanan Budi Mulia Palembang Tahun 2019.

\begin{tabular}{clrc}
\hline No & Pengetahuan & F & Persentase \\
\hline 1. & Baik & 15 & 22,4 \\
\hline 2. & Kurang & 52 & 77,6 \\
\hline & Jumlah & $\mathbf{6 7}$ & $\mathbf{1 0 0 , 0}$
\end{tabular}

Berdasarkan tabel 2 diatas mahasiswi yang berpengetahuan baik sebanyak 15 responden $(22,4 \%)$ dan mahasiswi yang berpengetahuan kurang sebanyak 52 responden $(77,6 \%)$.

\section{Anemia}

Berdasarkan hasil penelitian yang dilakukan pada 67 mahasiswi Akademi Kebidanan Budi Mulia Palembang tahun 2019, anemia dibagi menjadi 2 kategori yaitu anemia (apabila kadar $\mathrm{Hb}<12$ gr\%) dan tidak anemia (apabila kadar $\mathrm{Hb} \geq 12$ gr\%), untuk lebih jelasnya dapat dilihat pada tabel 3 . 
Tabel 3 Distribusi Frekuensi Berdasarkan Anemia Di Akademi Kebidanan Budi Mulia Palembang Tahun 2019

\begin{tabular}{rcrl}
\hline No & Anemia & F & Persentase \\
\hline 1. & Anemia & 25 & 37,3 \\
\hline 2. & Tidak Anemia & 42 & 62,7 \\
\hline & Jumlah & $\mathbf{6 7}$ & $\mathbf{1 0 0 , 0}$ \\
\hline & Berdar
\end{tabular}

Berdasarkan tabel 3 mahasiswi yang anemia sebanyak 25 responden $(37,3 \%)$ dan mahasiswi yang tidak anemia sebanyak 42 responden $(62,7 \%)$.

\section{b. Analisis Bivariat}

\section{Hubungan antara Pengetahuan dengan} Kejadian Disminore.

Dilakukan Uji Statistik bivariat antara variabel dependen (kejadian Disminorea) dengan variabel independen (Pengetahuan). Hasil uji statistik dapat dilihat pada tabel 4 di bawah ini.

Tabe1 4 Hubungan Antara Pengetahuan dengan Kejadian Disminore pada Mahasiswi Akademi Kebidanan Budi Mulia Palembang Tahun 2019

\begin{tabular}{|c|c|c|c|c|c|c|c|c|}
\hline \multirow{3}{*}{$\begin{array}{l}\mathbf{N} \\
\mathbf{0}\end{array}$} & \multirow{3}{*}{ Pengetahuan } & \multicolumn{4}{|c|}{ Kejadian Disminorea } & \multirow{2}{*}{\multicolumn{2}{|c|}{ Total }} & \multirow{3}{*}{$\begin{array}{c}P \\
\text { value }\end{array}$} \\
\hline & & \multicolumn{2}{|c|}{ Disminorea } & \multicolumn{2}{|c|}{$\begin{array}{c}\text { Tidak } \\
\text { disminorea }\end{array}$} & & & \\
\hline & & $\mathbf{n}$ & $\%$ & $\mathbf{n}$ & $\%$ & $\mathbf{n}$ & $\%$ & \\
\hline 1 & Tinggi & 9 & 60 & 6 & 40 & 15 & 100 & \multirow{3}{*}{1,000} \\
\hline 2 & Rendah & 36 & 69,2 & 16 & 30,8 & 52 & 100 & \\
\hline & Total & 45 & - & 22 & - & 67 & & \\
\hline
\end{tabular}

Berdasarkan tabel 4 diatas dari 15 responden dengan pengetahuan baik yang mengalami disminore sebanyak 9 responden (60\%) dan pengetahuan baik yang tidak disminore sebanyak 16 responden $(30,7 \%)$ dari 52 responden dengan pengetahuan kurang yang mengalami disminore sebanyak 36 responden $(69,2 \%)$ dan pengetahuan kurang yang tidak disminore sebanyak 16 responden $(30,8 \%)$.

Berdasarkan hasil uji statistik Chi-Square didapatkan $p$ value $=1,000$ lebih besar dari nilai $\alpha=0,05$ artinya tidak ada hubungan bermakna antara pengetahuan dengan kejadian disminore.
Hubungan antara Anemia dengan Kejadian Disminore

Dilakukan Uji Statistik bivariat antara variabel dependen (kejadian Disminorea) dengan variabel independen (Anemia). Hasil uji statistik dapat dilihat pada tabel 5 di bawah ini.

Tabe1 5 Hubungan Antara Anemia dengan Kejadian Disminore pada Mahasiswi Di Akademi Kebidanan Budi Mulia Palembang Tahun 2019

\begin{tabular}{|c|c|c|c|c|c|c|c|c|}
\hline \multirow{3}{*}{$\begin{array}{l}\mathbf{N} \\
\mathbf{0}\end{array}$} & \multirow{3}{*}{ Anemia } & \multicolumn{4}{|c|}{ Kejadian Disminorea } & \multirow{2}{*}{\multicolumn{2}{|c|}{ Total }} & \multirow{3}{*}{$\begin{array}{c}P \\
\text { value }\end{array}$} \\
\hline & & \multicolumn{2}{|c|}{ Disminorea } & \multicolumn{2}{|c|}{$\begin{array}{c}\text { Tidak } \\
\text { disminorea }\end{array}$} & & & \\
\hline & & $\mathbf{n}$ & $\%$ & $\mathbf{n}$ & $\%$ & $\mathbf{n}$ & $\%$ & \\
\hline 1 & Anemia & 18 & 72 & 7 & 28 & 25 & 100 & \multirow{3}{*}{0,236} \\
\hline 2 & Tidak Anemia & 27 & 64,3 & 15 & 35,7 & 42 & 100 & \\
\hline & Total & 45 & - & 22 & - & 67 & & \\
\hline
\end{tabular}

Berdasarkan tabel 5 diatas dari 25 responden dengan anemia yang mengalami disminore sebanyak 18 responden $(72 \%)$ dan yang tidak disminore sebanyak 7 responden (28\%) dan dari 42 responden yang tidak anemia yang mengalami disminore sebanyak 27 responden $(64,3 \%)$ dan yang tidak disminore sebanyak 15 responden $(35,7 \%)$.

Berdasarkan hasil uji statistik Chi-Square didapatkan $p$ value $=0,236$ lebih besar dari nilai $\alpha=0,05$ artinya tidak ada hubungan bermakna antara pengetahuan dengan kejadian disminore.

\section{PEMBAHASAN}

\section{Kejadian disminore pada Mahasiswi Akademi kebidanan Budi Mulia Palembang}

Dismenore adalah kekakuan atau kejang dibagian bawah perut yang terjadi pada waktu menjelang atau selama menstruasi, yang memaksa wanita untuk beristirahat atau berakibat pada menurunnya kinerja dan berkurangnya aktifitas sehari-hari. ${ }^{5}$

Pada penelitian ini jumlah mahasiswi yang mengalami disminore lebih banyak $(67,2 \%)$ dibandingkan mahasiswi yang tidak mengalami disminore $(32,8 \%)$.

Banyaknya mahasiswi yang mengalami disminore bisa disebabkan oleh beberapa faktor antara lain faktor kejiwaan yang berkaitan dengan pengetahuan, faktor konstitusi yang berkaitan dengan anemia dan penyakit menahun serta faktor endokrin yang berkaitan dengan endometrium dalam fase sekresi memproduksi protaglandin $\mathrm{F}_{2}$-alfa yang menyebabkan kontraksi otot-otot polos. ${ }^{10}$ 


\section{Hubungan Antara Pengetahuan dengan Kejadian Disminore}

Dari hasil analisis bivariat responden dengan pengetahuan baik lebih sedikit $(22,4 \%)$, dibandingkan dengan responden pengetahuan kurang $(77,6 \%)$. Responden dengan pengetahuan baik yang mengalami disminore lebih banyak (60\%) dibandingkan dengan yang tidak disminore $(40 \%)$ dan responden dengan pengetahuan kurang yang mengalami disminore lebih banyak $(69,2 \%)$ dibandingkan dengan yang tidak disminore (30,8\%).

Dari hasil uji statistik Chi-Square tidak terdapat hubungan yang bermakna antara pengetahuan dengan kejadian disminore di Akademi Kebidanan Budi Mulia Palembang tahun 2019 dimana diperoleh $p$ value $=1,000$ lebih besar dari $\alpha=0,05$ sehingga hipotesa mengatakan ada hubungan antara pengetahuan dengan kejadian disminore tidak terbukti secara statistik.

Hasil penelitian tidak sejalan dengan penelitian Dyah Pradnya Paramita (2010) yang menyatakan bahwa terdapat hubungan antara tingkat pengetahuan tentang dismenorea dengan perilaku penanganan dismenorea pada siswi SMK YPKK I Sleman Yogyakarta. Sebanyak $46(79,3 \%)$ siswi memiliki tingkat pengetahuan cukup dan berperilaku baik dalam menangani dismenorea. Adanya hubungan antara kedua variabel ditunjukkan dari hasil perhitungan uji korelasi Kendall's tau dengan tingkat kesalahan $5 \%$, didapatkan nilai korelasi Kendall's tau $=0,510$ dan nilai $p=0,000$.

Dari hasil penelitian yang di lakukan di Akademi Kebidanan Budi Mulia Palembang tahun 2019, bahwa tingkat pengetahuan mahasiswi tentang disminore sudah baik karena mereka banyak mendapatkan informasi tentang pencegahan dan pengobatan tentang disminore pada mata kuliah kesehatan reproduksi di Akademi Kebidanan Budi Mulia Palembang. Sehingga kejadian disminore dapat ditanggulangi.

\section{Hubungan Antara Anemia dengan Kejadian Disminore}

Dari hasil analisis bivariat responden yang anemia lebih sedikit (37,3\%), dibandingkan dengan responden yang tidak anemia $(62,7 \%)$. Responden dengan anemia yang mengalami disminore lebih banyak (72\%) dibandingkan dengan yang tidak disminore $(28 \%)$ dan responden dengan tidak anemia yang mengalami disminore lebih banyak $(64,3 \%)$ dibandingkan dengan yang tidak disminore $(35,7 \%)$.

Dari hasil pengujian statistik dengan menggunakan Chi-Square tidak terdapat hubungan yang bermakna antara anemia dengan kejadian disminore di Akademi Kebidanan Budi Mulia Palembang tahun 2019 dimana diperoleh p.value $=0,236$ lebih besar dari $\alpha=(0,05)$ sehingga hipotesa yang mengatakan ada hubungan antara anemia dengan kejadian disminore tidak terbukti secara statistik.

Hasil penelitian ini tidak sejalan dengan hasil penelitian Risman (2004), uji ChiSquare menunjukkan ada hubungan pola menstruasi dengan kejadian anemia $\left(X^{2}=29,891 ; \alpha=0,001\right)$. Apabila darah yang keluar selama menstruasi sangat banyak akan mengakibatkan terjadinya anemia defisiensi besi.

Dari hasil penelitian yang dilakukan di Akademi Kebidanan Budi Mulia Palembang Tahun 2019 dengan menggunakan pemeriksaan Hemoglobin (HB) Sahli secara langsung kepada mahasiswi, bahwa mahasiswi yang kadar hemoglobin < 12 gr\% tidak mengalami disminore setiap menstruasi, karena banyak faktor-faktor lain yang mempengaruhi misalnya keadaan psikologis yang tidak stabil sehingga mereka cenderung tidak memperhatikan kebutuhan nutrisi dan gizi, dan dari hasil pemeriksaan Hemoglobin (HB) didapatkan mahasiswi dengan anemia termasuk dalam anemia ringan sehingga tidak terlalu mempengaruhi keadaan nyeri pada saat menstruasi, dengan kata lain mereka tidak mengalami disminore.

\section{KESIMPULAN}

Berdasarkan hasil penelitian di Akademi Kebidanan Budi Mulia Palembang Tahun 2019 yang berjudul hubungan antara pengetahuan dan anemia terhadap kejadian disminore pada Mahasiswi Akademi Kebidanan Budi Mulia Palembang Tahun 2019 dengan sampel sebanyak 67 mahasiswi didapatkan hasil penelitian sebagai berikut : Distribusi frekuensi responden yang mengalami kejadian disminore sebanyak 45 responden $(67,2 \%)$ dan tidak disminore sebanyak 22 responden (32,8\%), Distribusi frekuensi responden, dengan pengetahuan baik sebanyak 15 responden $(22,4 \%)$ dan responden dengan berpengetahuan kurang sebanyak 52 
responden (77,6\%). Distribusi frekuensi responden yang mengalami anemia sebanyak 25 responden $(37,3 \%)$ dan tidak anemia sebanyak 42 responden $(62,7 \%)$. Tidak ada hubungan yang bermakna antara pengetahuan dengan kejadian disminore di Akademi Kebidanan Budi Mulia Palembang Tahun 2019 dengan $P$ value 1,000. Tidak ada hubungan yang bermakna antara anemia dengan kejadian disminore di Akademi Kebidanan Budi Mulia Palembang Tahun 2019 dengan $P$ value 0,236 .

\section{SARAN}

1. Bagi Akademi Kebidanan Budi Mulia Palembang

Diharapkan hasil penelitian ini dapat dijadikan masukan untuk menambah ilmu pengetahuan bagi dosen dan mahasiswi Akademi Kebidanan Budi Mulia Palembang dan juga sebagai bahan pustaka terkait dengan masalah disminore.

2. Bagi Peneliti Yang Akan Datang

Diharapkan dapat lebih menggali dan mengembangkan teori-teori tentang disminore dan menambah variabel yang diteliti seperti faktor kejiwaan yang berkaitan dengan pengetahuan, faktor konstitusi yang berkaitan dengan anemia dan penyakit menahun.

\section{DAFTAR PUSTAKA}

1. Manuaba, Ida Bagus Gde, 2017. Ilmu Kebidanan, Penyakit Kandungan dan Keluarga Berencana, Jakarta : Buku Kedokteran.

2. Prawirohardjo, Sarwono, 2018. Metodologi Penelitian Kesehatan. Jakarta : Rineka Cipta.

3. Anolis, Andhita Caya, 2011. 17 Penyakit Wanit yang Paling Mematikan.

4. Glasier, Anna, 2006. Keluarga Berencana dan Kesehatan Reproduksi. Jakarta : EGC.

5. Proverawati, Atikah.2011. Anemia dan Anemia Kehamilan. Nuha Medika: Yogyakarta.

6. Kusmiran, Eny, 2011. Kesehatan Reproduksi Remaja dan Wanita. Jakarta : Salemba Medika.

7. Tanujaya, Edward, 2010. Kesehatan Remaja Problem dan Solusinya. Jakarta : Salemba Medika
8. Haryanto, 2010. Metodologi Penelitian Kesehatan. Jakarta : Rineka Cipta.

9. Notoatmodjo, Soekidjo. 2018. Metodelogi Penelitian Kesehatan. Rineka Cipta : Jakarta

10.Laila, Nur Najmi, 2011. Buku Pintar Menstruasi. Jogjakarta : Buku Biru.

11.Handayani, Wiwik, 2008. Hematologi. Jakarta : Salemba Medika.

12.Paramita, Dyah Pradnya, 2010. Hubungan Tingkat Pengetahuan Tentang Disminore dengan Perilaku Penanganan Disminore pada Siswi SMK YPKK I Sleman Yogyakarta. KTI Universitas Sebelas Maret Surakarta, 2010.

13.Corwin, Elizabeth. J, 2009. buku Saku Patofisiologi. Jakarta : Buku Kedokteran.

14.Wiknjosastro, Hanifa, 2008. Ilmu Kandungan. Jakarta : Bina Pustaka.

15.http://www.scribd.com/doc/79349579/angkakejadian-dismenore.

16.http://www.spesialis.info/?masalah-kesehatanwanita.43.

17.http:www.lusa.wbe.id/dismenoredysmenorhea-part-1. 
